Risky emotional family environment in childhood and depression-related cytokines in adulthood: The protective role of compassion

\title{
Saarinen, Aino
}

2021-07

Saarinen, A, Keltikangas-Jarvinen , L, Dobewall , H , Ahola-Olli , A , Salmi , M , Lehtimäki , T, Raitakari , O , Jalkanen, S \& Hintsanen, M 2021, ' Risky emotional family environment in childhood and depression-related cytokines in adulthood: The protective role of compassion ' , Developmental Psychobiology , vol. 63 , no. 5 , pp. 1190-1201 . https://doi.org/10.1002/dev.22070

http://hdl.handle.net/10138/338363

https://doi.org/10.1002/dev.22070

acceptedVersion

Downloaded from Helda, University of Helsinki institutional repository.

This is an electronic reprint of the original article.

This reprint may differ from the original in pagination and typographic detail.

Please cite the original version. 
Risky emotional family environment in childhood and depression-related cytokines in adulthood: the protective role of compassion

Running title: Family environment and cytokines

Aino Saarinen ${ }^{1,2, *}$, Liisa Keltikangas-Järvinen ${ }^{2}$, Henrik Dobewall ${ }^{1}$, Ari Ahola-Olli ${ }^{3,4,5}$, Marko Salmi ${ }^{6}$, Terho Lehtimäki ${ }^{7}$, Olli Raitakari ${ }^{8,9,10}$, Sirpa Jalkanen ${ }^{6}$, Mirka Hintsanen ${ }^{1}$

${ }^{1}$ Research Unit of Psychology, University of Oulu, Finland ${ }^{2}$ Department of Psychology and Logopedics, Faculty of Medicine, University of Helsinki, Finland ${ }^{3}$ Stanley Center for Psychiatric Research, Broad Institute of MIT and Harvard, Cambridge, MA, USA ${ }^{4}$ Psychiatric and Neurodevelopmental Genetics Unit, Department of Psychiatry, Massachusetts General Hospital, Boston, MA, USA ${ }^{5}$ Institute for Molecular Medicine Finland (FIMM), University of Helsinki, Helsinki, Finland ${ }^{6}$ MediCity Research Laboratory and Institute of Biomedicine, University of Turku, Turku, Finland ${ }^{7}$ Department of Clinical Chemistry, Fimlab Laboratories and Finnish Cardiovascular Research Center-Tampere, Faculty of Medicine and Health Technology, Tampere University, Finland ${ }^{8}$ Centre for Population Health Research, University of Turku and Turku University Hospital, Turku, Finland. ${ }^{9}$ Research Centre of Applied and Preventive Cardiovascular Medicine, University of Turku, Turku, Finland. ${ }^{10}$ Department of Clinical Physiology and Nuclear Medicine, Turku University Hospital, Turku, Finland.

* Correspondence to: Aino Saarinen. Department of Psychology and Logopedics, Faculty of Medicine, Haartmaninkatu 3, P.O. Box 21, 00014 University of Helsinki, Finland. E-mail: aino.i.saarinen@helsinki.fi, Tel.: +35844 3071204. 


\section{Acknowledgements}

This study was supported financially by the Academy of Finland (M.H., grant number 308676). The Young Finns Study has been financially supported by the Academy of Finland: Grants 286284, 134309 (Eye), 126925, 121584, 124282, 129378 (Salve), 117797 (Gendi), and 41071 (Skidi); the Social Insurance Institution of Finland; Competitive State Research Financing of the Expert Responsibility area of Kuopio, Tampere and Turku University Hospitals (grant X51001); the Juho Vainio Foundation; the Sigrid Juselius Foundation; the Yrjö Jahnsson Foundation; the Paavo Nurmi Foundation; the Finnish Foundation of Cardiovascular Research and Finnish Cultural Foundation; the Tampere Tuberculosis Foundation; the Emil Aaltonen Foundation; and Diabetes Research Foundation of Finnish Diabetes Association.

\section{Role of the funding sources}

The funding source had no role in study design, data collection, data analysis, data interpretation, writing of the report, or in the decision to submit the article for publication.

\section{Conflict of interest}

None. 


\begin{abstract}
Background: Previously, compassion has been found to protect against depressive symptoms, while emotional adversities in childhood are suggested to increase inflammatory responses. The current study investigated (i) whether emotional family environment in childhood predicts levels of such cytokines in adulthood that are previously found to be elevated in depression (IL-2, IL-6, IL-1b, MCP-1, IFN- $\gamma$, and TNF- $\alpha$ ) and (ii) whether these associations are modified by compassion in adulthood. Methods: The participants $(\mathrm{N}=1198-1523)$ came from the prospective population-based Young Finns data. Emotional family environment and parental socioeconomic factors were evaluated in 1980; participants' compassion in 2001; and participants' cytokine levels and adulthood covariates in 2007. Results: Risky emotional family environment in childhood predicted higher levels of IL-2, IL-6, IFN- $\gamma$, and TNF- $\alpha$ in adulthood. Additionally, there were significant interaction effects between compassion and emotional risk in childhood, when predicting IL-2, IL-6, and TNF- $\alpha$. Specifically, individuals who grew up in a risky emotional family environment had on average higher levels of IL-2, IL-6, and TNF- $\alpha$ in adulthood when combined with low compassion. Conclusions: In individuals coming from risky emotional family environments, high compassion for others may protect against elevated levels of cytokines previously linked with depression.
\end{abstract}

\title{
Keywords
}

Family environment; Emotional environment; Childhood environment; Personality; Cytokines; Inflammation 


\section{Introduction}

Inflammatory changes have received increasing interest as etiological factors predisposing to depression. In the recent years, meta-analyses have suggested that anti-inflammatory treatments seem to effectively reduce depressive symptoms without significant risks for adverse side effects, particularly in individuals with early depressive episodes (Fond et al., 2014; Köhler et al., 2014). Further, there has been a demand for "an anti-inflammatory strategy for depression", suggesting that anti-inflammatory drugs could be provided as additional treatments with traditional anti-depressants (Hayley, 2011). To date, there is general consensus in the field that the circulating levels of cytokines interleukin-1b (IL-1b), interleukin-2 (IL-2), interleukin-6 (IL-6), monocyte chemoattractant protein-1 (MCP-1), interferon-gamma (IFN- $\gamma$ ), and tumor necrosis factor alpha (TNF- $\alpha$ ) are elevated in depression (e.g. Dowlati et al., 2010; Mills et al., 2013; Young et al., 2014).

There is accumulating evidence that childhood adversity, which represents a risk factor for depression per se, may set the basis for the functioning of inflammatory system from childhood to adulthood. Firstly, there is a great amount of evidence from prospective studies that low physical home quality and the absence of positive parental monitoring and supervision predict higher C-reactive protein (CRP) (Schmeer \& Yoon, 2016) and higher secretory immunoglobulin later in childhood (Byrne et al., 2017), respectively. Finally, previous studies have shown that childhood adversities such as exposure to interpersonal conflict (Reid et al., 2020), childhood victimization (Baldwin et al., 2018), physical abuse (Pereira et al., 2019), being bullied by peers (Takizawa et al., 2015), cumulative exposure to childhood maltreatment (Danese et al., 2017), and child's emotional problems (Appleton et al., 2012) predict higher CRP also in adolescence or adulthood. Consequently, two meta-analyses have indicated that childhood maltreatment appears to be associated with a chronically higher level of CRP over the life-span (Coelho et al., 2013; Kuhlman et al., 2019). 
Thus, while the link between childhood adversities and higher CRP seems to be apparent, evidence is limited about the relationship of childhood adversities with cytokine levels. A metaanalysis indicated that exposure to trauma in childhood is related to higher TNF- $\alpha$ levels in adulthood (Baumeister et al., 2016) but two meta-analyses have resulted in inconclusive findings whether early adversity predicts elevated IL-6 levels or not (Baumeister et al., 2016; Kuhlman et al., 2019). Also, there is preliminary evidence that traumatic life events and contextual stressors are associated with elevated IL-1 $\beta$ (Tyrka et al., 2015). Further, growing up in a harsh family environment seems to be related to higher resistance of glucocorticoids (Miller \& Chen, 2010). Most of the studies, however, have included a retrospective study design. In addition, most previous studies have measured inflammation with the cytokines of IL-1 $\beta$, IL-6 or TNF- $\alpha$ (Baumeister et al., 2016; Carpenter et al., 2010; Kiecolt-Glaser et al., 2011; Rooks et al., 2012; Tyrka et al., 2015). On the contrary, it has remained unclear whether childhood adversities predict also other cytokines that are known to predispose to depression, such as IL-2, MCP-1, and IFN- $\gamma$.

Some individuals, however, might be more prone to increased inflammatory responses than others (Colodro-Conte et al., 2018). Evidence is scarce whether psychosocial factors in adulthood could help to prevent elevated inflammation levels among individuals coming from risky family environments. To date, there is evidence that the association of childhood adversities or child's emotional problems with inflammation in adulthood may be modified by family socioeconomic status (Appleton et al., 2012) or emotional environment in adolescence (do Prado et al., 2012). At least to our knowledge, no previous study has investigated whether personality traits could modify the link between the emotional family environment and inflammation.

Compassion for others might be an essential trait protecting against elevated levels of depression-related cytokines. Compassion for others is defined as a disposition to feel concern for other's suffering that is followed by the desire to alleviate the suffering and improve other's well-being 
(Goetz et al., 2010). It is a separate concept from self-compassion (i.e. compassionate attitude toward the suffering of the self) (Barnard \& Curry, 2011) and compassion from others (i.e. compassionate expressions received from others for the suffering of the self) (Gilbert, 2019). Compassion for others predicts lower depression (Saarinen et al., 2019) and, previously, intervention studies have demonstrated that compassion-training interventions are linked to decreased concentrations of CRP and decreased responses of IL-6, cortisol, and adrenocorticotropic hormone (ACTH) to psychosocial stress (Abelson et al., 2014; Pace et al., 2009). Finally, compassionate states correlate with the activity of hypothalamus (Immordino-Yang et al., 2009) that is involved in the regulation of inflammatory responses (Black, 2002).

The aim of the current study was to investigate whether emotional family environment in childhood predicts the cytokine levels in adulthood, and whether these associations are modified by compassion. In this study, we investigated the cytokines IL-1b, IL-2, IL-6, MCP-1, IFN- $\gamma$, and TNF- $\alpha$ that are shown to be elevated in depression (e.g. Dowlati et al., 2010; Mills et al., 2013; Young et al., 2014). We used intergenerational data with a 27 -year prospective follow-up. The data provided possibilities to take into consideration a variety of potential confounders, including age, sex, the use of anti-inflammatory medications, and inflammatory diseases, socioeconomic factors (in childhood and adulthood), body-mass index, health behavior (smoking, alcohol use, alcohol intoxication, physical activity), and depressive symptoms.

\section{Material and methods}

\subsection{Participants}

The participants came from the prospective Young Finns Study. The participants were selected randomly from the population register of the Social Insurance Institution from six age cohorts (born 
between 1962-1977). The Social Insurance Institution covers the whole population of Finland. The original sample included 3596 participants in the baseline measurement in 1980 (when participants were aged 3-18 years). The participants have been followed since then so that the latest follow-up measurement was in 2011 (participants were aged 34-49 years). The study was carried out in accordance with the Declaration of Helsinki. Furthermore, the design of the Young Finns Study was approved by the ethical committees of all the Finnish universities with medical schools. Before participation, all the participants or their parents (for participants aged below 12 years) provided informed consent after the nature of the procedures had been fully explained. The design of the Young Finns Study is described with more detail elsewhere (see Raitakari et al., 2008).

For this study, emotional family environment and parental socioeconomic factors were evaluated in 1980; participants' compassion in 2001; and participants' cytokine levels, body-mass index, health behavior, socioeconomic factors, depressive symptoms, anti-inflammatory medications, and inflammatory diseases in 2007. Participants who were pregnant at the measurement time of cytokines (in 2007) were excluded from the analyses ( $N=37)$. The study design is illustrated in Supplementary Figure 1. In the analyses, sample size ranged between 1198 (analyses adjusted with baseline covariates) and 1523 participants (fully-adjusted analyses).

\subsection{Measures}

\subsubsection{Emotional family environment in childhood}

Emotional family environment was measured with a risk score that has been used also previously (Pulkki-Råback et al., 2015). The risk score of emotional family environment was calculated as the sum score of 4 dichotomous indicators (measured in 1980): (i) parents' low life satisfaction, (ii) risky parental intoxication, (iii) parental mental disorder, and (iv) hostile parenting attitudes. Parental life satisfaction was evaluated with a 3-item questionnaire asking about parents' life satisfaction as a 
spouse, parent, and employee. The items were responded with a 5-point scale $(1=$ satisfied;

$5=$ dissatisfied). Parental life dissatisfaction was defined to be present if the parent reported being unsatisfied ("dissatisfied" or "quite dissatisfied") in any of the life sectors ( $0=$ satisfied; $1=$ parental dissatisfaction present). Parental alcohol intoxication was evaluated by asking the frequency of intoxication with a 8 -point scale ( $1=$ daily; $8=$ never). Risky parental intoxication was defined to be present if at least one parent reported being intoxicated once a week or more frequently. Parental mental disorders were measured by asking the parents whether they had ever been diagnosed with a mental disorder by a doctor $(0=$ no; $1=$ yes $)$. Parental mental disorder was defined to be present if at least one parent reported being diagnosed with a mental disorder. Hostile parenting was evaluated with a 8item questionnaire (e.g. "The child is a burden in challenging situations") that was responded with a 5point scale ( $1=$ never; $5=$ often). Hostile parenting was defined to be present if the parent responded to at least one item with "often" or "quite often".

\subsubsection{Dispositional compassion}

Dispositional compassion for others was evaluated in 2001 with the version 9 of the Temperament and Character Inventory (TCI) (Cloninger et al., 1994). The compassion scale consists of 10 self-rating statements (e.g., "It gives me pleasure to see my enemies suffer" [reverse scored], "It gives me pleasure to help others, even if they have treated me badly" [positively scored], "I like to imagine my enemies suffering" [reverse scored] and "I hate to see anyone suffer" [positively scored]). The items were rated with a 5 -point Likert-scale ( $1=$ completely disagree; $5=$ completely agree). The score of compassion was calculated for all the participants with data on at least $50 \%$ of the items. The construct validity, internal consistency, test-retest reliability, and predictive validity of the compassion scale are found to be very good (see a more detailed description in Saarinen et al., 2019). 


\subsubsection{Cytokines}

Cytokine levels were measured from unthawed serum samples. The measurement of cytokines in the Young Finns Study (YFS) is described with detail previously (Santalahti et al., 2016). From YFS, a total of 48 cytokines were measured by using Bio-Rad's premixed Bio-Plex Pro Human Cytokine 27plex Assay and 21-plex Assay, and Bio-Plex 200 reader with Bio-Plex 6.0 software. The assays were performed according to manufacturer's instructions, except that the amount of beads, detection antibodies, and streptavidin-phycoerythrin conjugate were used with 50\% lower concentrations than recommended. The validity of this approach has been demonstrated elsewhere (Ahola-Olli et al., 2017; Nieminen et al., 2104; Pietikäinen et al., 2016; Santalahti et al., 2016, 2017). In this study, only the cytokines IL-1b, IL-2, IL-6, MCP-1, IFN- $\gamma$, and TNF- $\alpha$ shown to be elevated in depression (e.g. Dowlati et al., 2010; Mills et al., 2013; Young et al., 2014) were investigated. Over 99\% of the samples gave values within the cytokine-specific detection range for each of the cytokines analyzed here. In the analyses, we used logarithm-transformed variables of the cytokine levels.

\subsubsection{Covariates}

Covariates included parents socioeconomic factors (in 1980) and participants' socioeconomic factors (level of income and educational level), participants' body-mass index, health behavior (smoking, alcohol use, alcohol intoxication, physical activity), depressive symptoms, anti-inflammatory medications, and inflammatory diseases (all the adulthood covariates were measured in 2007). Socioeconomic factors included participants' and their parents' level of income and educational level. Educational level was classified into 3 categories $(1=$ comprehensive school; $2=$ high school or occupational school; 3=academic level). In case mother's and father's educational level different from each other, we used the higher educational level. Level of parental income (household income) included 8 categories $(1=$ less than 15000 Finnish mark per year; $8=$ more than 100000 
Finnish mark per year). Participants' level of income was assessed with a 8-point scale (1=less than $10000 €$ per year; $8=$ more than $70000 €$ per year).

Body-mass index (BMI) was calculated as weight $(\mathrm{kg})$ divided by height squared $\left(\mathrm{m}^{2}\right)$. Participants' health behavior (smoking, alcohol use, physical activity) were evaluated with self-rating questionnaires. The frequency of smoking was evaluated with a 5-point scale ( $1=$ never; 5=daily). Alcohol use was evaluated with the frequency ( $1=$ never, $5=$ daily) of consuming six types of alcohol drinks: (i) small beer; (ii) beer with the alcoholic content $2.8 \%-4.7 \%$ of its volume; (iii) beer with the alcoholic content max 5.5\%; (iv) wine; (v) cider or long-drink; and (vi) liquor. We calculated a mean score of the subscales for all the participants who had responded to at least $50 \%$ of the items. The frequency of alcohol intoxication (consumption of 6 or more portions at an occasion) was evaluated with a 6 -point scale ( $1=$ at most 5 times per year; $6=$ at least two times per week). Physical activity was evaluated with a 5-item scale that can be found in the Supplementary Material (see also Hirvensalo et al., 2017). We calculated the sum score of the 5 items for all the participants who had responded to at least $50 \%$ of the items. In our sample, the internal consistency of the scale of physical activity was $\alpha=.74$.

Depressive symptoms were evaluated with a modified version of the Beck Depression Inventory (BDI) (Beck et al., 1996). The questionnaire consists of the second mildest statements of the BDI. The statements were responded with a 5 -point Likert-scale ( $1=$ totally disagree; $5=$ totally agree). The questionnaire is described with further detail elsewhere (see Elovainio et al., 2005). We calculated the mean score of the items for all the participants who had responded to at least $50 \%$ of the items.

Anti-inflammatory medications included statins, non-steroidal anti-inflammatory drugs, and anti-rheumatoid drugs. Inflammatory diseases included type I or II diabetes, Crohn's disease, rheumatoid arthritis, and fibromyalgia. We calculated a dichotomous score of anti-inflammatory medications $(0=$ no anti-inflammatory medications; $1=$ at least one anti-inflammatory medication $)$ and 
inflammatory diseases $(0=$ no inflammatory diseases; $1=$ at least one inflammatory disease $)$.

\subsection{Statistical analyses}

Statistical analyses were conducted with STATA SE (version 13.0). We analyzed the data with multivariate multiple regression analyses where all the cytokines were set as outcomes simultaneously. This was done because of correlations between single sytokines (see Santalahti et al., 2016). We used logarithm-transformed values of cytokines in order to decrease skewness of the distributions. Participants who were pregnant at the measurement time of cytokines were excluded from the analyses. Firstly, we predicted cytokines by emotional family environment in childhood. Secondly, we investigated whether compassion modifies this association by adding the main effect of compassion and the interaction effect between compassion and emotional family environment to the model. Models 1 were adjusted for age, sex, the use of anti-inflammatory medications, and inflammatory diseases. Models 2 were adjusted also for socioeconomic factors in childhood and adulthood, body-mass index, health behavior (smoking, alcohol use, alcohol intoxication, physical activity), and depressive symptoms.

\section{Results}

The descriptive statistics of the study variables are shown in Table 1. Attrition analyses showed that women were more likely to participate than men ( 47.8 vs. $36.7 \%, p<.001)$, and subjects without an inflammatory disease were slightly more likely to participate than subjects with an inflammatory disease $(69.0 \%$ vs. $68.8 \%, \mathrm{p}<.01)$. There was no attrition bias in compassion, emotional risk in childhood, cytokine levels, level of income, frequency of alcohol use, level of depressive symptoms, or in the use of anti-inflammatory drugs. Included participants were slightly older (31.7 vs. 31.3 years, 
$\mathrm{p}<.05$ ), had slightly lower body-mass index ( 25.8 vs. $26.4, p<.01)$, were more active physically ( 9.6 vs. $9.4, p<.05)$, had less frequent alcohol intoxication (2.4 vs. $2.6, p<.01)$, and were less likely to have low educational level $(4.0 \%$ vs. $6.9 \%, p<.001)$. Included participants' parents had slightly higher level of income ( 4.9 vs. $4.7, p<.05)$ and were less likely to have low educational level $(31.9 \%$ vs. $36.8 \%, p<.01)$ than excluded participants' parents.

\section{(TABLE 1 AROUND HERE)}

The results of the regression analyses are shown in Tables 2 and 3. First, we investigated whether emotional family environment in childhood predicts the cytokine levels in adulthood (IL-2, IL-6, IL-1b, MCP-1, IFN- $\gamma$, and TNF- $\alpha$ ). When adjusted for age, sex, anti-inflammatory medications, and inflammatory diseases (see Table 2, Model 1), a risky family emotional environment predicted higher levels of IL-2, IL-6, IFN- $\gamma$, and TNF- $\alpha$ but not IL-1b or MCP-1. The significant associations remained in the fully-adjusted models (adjusted also for socioeconomic factors in childhood and adulthood, body-mass index, health behavior, and depressive symptoms) (see Table 1, Model 2).

Next, we investigated whether compassion modifies the associations of emotional family environment in childhood with the cytokine levels in adulthood. When adjusted for age, sex, antiinflammatory medications, and inflammatory diseases (see Table 2, Model 1), there was a significant negative interaction effect between compassion and emotional family environment, when predicting the levels of IL-2, IL-6, and TNF- $\alpha$. The interaction was not significant when predicting IL-1b, MCP-1, or IFN- $\gamma$. In the fully-adjusted models (adjusted also for socioeconomic factors in childhood and adulthood, body-mass index, health behavior, and depressive symptoms), all the significant interaction effects remained. The findings are illustrated in Figure 1. 
As additional analyses, we reran the fully-adjusted interaction analyses using structural equation modeling and full-information maximum likelihood (FIML) estimation, in order to examine whether the results are replicated if using another method (a less stringent method) of handling missing values. We included all the participants who were not pregnant and who had data available on at least one cytokine $(\mathrm{N}=2163)$. No restrictions were set on missing values of the other variables. All the cytokines were set as dependent variables simultaneously (the variances between the error terms of the cytokines were included in the model). We set regression paths from risky emotional family environment, compassion, their interaction, and all the control variables to the cytokines. All the variables were set as observed variables in the model. The results are presented in Supplementary Table 1. All the significant main effects of compassion and risky emotional family environment on the cytokines remained. Further, all the significant interactions between compassion and emotional family environment on the cytokines remained.

As additional analyses, we reran the analyses without controlling for depressive symptoms. All the significant interactions between risky emotional family environment and compassion remained when predicting cytokine levels (see Supplementary Table 2).

The main effects of compassion (without considering emotional family environment in childhood) are shown in Supplementary Table 3. Compassion did not have significant main effect on cytokine levels.

Finally, we investigated whether sex modifies the association of emotional family environment and compassion with cytokines. There was no significant three-way interaction effect of sex*emotional family environment*compassion), when predicting IL-2 ( $p=0.127)$, IL-6 ( $p=0.261)$, IL$1 b(p=0.570), \operatorname{MCP}-1(p=0.544), \operatorname{IFN}-\gamma(p=0.160)$, or TNF- $\alpha(p=0.699)$.

\section{(TABLE 2 AROUND HERE)}


(TABLE 3 AROUND HERE)

(FIGURE 1 AROUND HERE)

\section{Discussion}

This study showed that individuals coming from a risky emotional family environment in childhood (including parents' low life satisfaction, risky parental intoxication, parental mental disorder, and hostile parenting attitudes) have on average higher levels of IL-2, IL-6, IFN- $\gamma$, and TNF- $\alpha$ in adulthood. Moreover, we found that compassion modifies the association of risky emotional family environment with cytokine levels in adulthood. That is, individuals with a risky emotional family environment in childhood and with low compassion have higher levels of IL-2, IL-6, and TNF- $\alpha$, which in turn have previously found to be linked to depression (e.g. Dowlati et al., 2010; Mills et al., 2013; Young et al., 2014). Instead, in individuals with high compassion, risky emotional family environment did not predict elevated levels of these cytokines. These associations were obtained independently of age, sex, anti-inflammatory drugs, inflammatory diseases, socioeconomic factors in childhood and adulthood, body-mass index, and health behavior (smoking, alcohol use, alcohol intoxication, physical activity), and depressive symptoms. Overall, the study demonstrated that risky emotional environment in childhood predicts higher levels of such cytokines that have been previously linked to depression (e.g. Dowlati et al., 2010; Mills et al., 2013; Young et al., 2014), but high compassion may act as a preventive factor.

The association of a risky emotional family environment in childhood with elevated cytokine levels in adulthood is in accordance with previous studies. Firstly, childhood adversity is demonstrated to predict elevated stress sensitization in later life, i.e. increased vulnerability to the 
adverse influences of psychosocial stressors (McLaughlin et al., 2010). Chronic experiences of psychosocial stress, in turn, commonly result in maladaptive changes in the functioning of hypothalamus-pituitary-adrenal (HPA) axis (Fagundes \& Way, 2014; Tian et al., 2014) that is known to be responsible for the regulation of physiological stress responses. Further, there is a close reciprocal interaction between the dysregulation of the HPA axis and excretion of some cytokines, such as IL-6 and TNF- $\alpha$ (Padgett \& Glaser, 2003; Tian et al., 2014). Importantly, there may exist also epigenetic pathways from risky family environment to elevated inflammatory responses. For example, childhood adversities are found to predict the DNA methylation of some inflammation-related genes in adulthood (McDade et al., 2017). Finally, our findings are in line with previous results from the Young Finns Study showing that early adversity (e.g. hostile parenting or adverse psychosocial family environment) is related to higher risk for depressive symptoms (Gluschkoff et al., 2017) and less favorable cardiovascular health (Pulkki-Råback et al., 2015).

Importantly, the pathway from childhood adversities to elevated cytokine levels seems not to be inevitable. Specifically, our findings showed that high compassion may protect against elevation of depression-related cytokines in individuals coming from risky emotional family environment. This supports the diathesis-stress model for depression (Colodro-Conte et al., 2018). The favorable effect of compassion on cytokine levels is in line with previous literature showing that compassion is related to lower physiological stress responses. That is, compassion-training is linked to reduced concentrations of CRP and decreased responses of IL-6, cortisol, and adrenocorticotropic hormone (ACTH) to psychosocial stress (Abelson et al., 2014; Pace et al., 2009). Nevertheless, it is necessary to consider that early adversities may have adverse influences simultaneously on compassion and cytokine levels. For example, hostile parenting is shown to predict lower developmental trajectory of compassion in adulthood (Hintsanen et al., 2019). Hence, in order to reach a high level of compassion, individuals coming from risky family environments may need some compensatory factors 
or psychological interventions. Fortunately, compassion-training is demonstrated to increase compassion in a relatively short time period in adulthood, even within 9 weeks (Jazaieri et al., 2013; Kirby et al., 2017).

Also, it is necessary to consider that individuals from risky family environments have likely not received compassion from their parents as much as they would have needed. Accordingly, low parental warmth and early memories of shame or traumatic experiences are related to higher fear of compassion (Kelly \& Dupasquier, 2016; Matos et al., 2017) that, in turn, increases risk for depressive symptoms, anxious, and paranoid symptoms (Hermanto et al., 2016; Matos et al., 2017). Further, a meta-analysis indicated that individuals with clinical psychiatric symptoms (e.g. depression) may not have fears for providing compassion for others but, rather, they are more likely to have fears in receiving compassion from others (Kirby et al., 2019). Future studies could investigate the role of fear of compassion in protecting against elevated inflammatory responses.

As there are complicated interplays between different cytokines, the cytokines that were examined here may have various chain effects and influence the dynamic interaction between other cytokines (Santalahti et al., 2016). Even though there is a great amount of evidence that elevated levels of the cytokines of IL-2, IL-6, IL-1b, MCP-1, IFN- $\gamma$, and TNF- $\alpha$ are linked to depression (e.g. Dowlati et al., 2010; Mills et al., 2013; Young et al., 2014), some of the examined cytokines are also related to other psychiatric and somatic disorders. For example, some of these cytokines seem to be related to higher risk for cancer (Coussens \& Werb, 2002), cardiovascular diseases (Pearson et al., 2003), diabetes (Wellen \& Hotamisligil, 2005), bipolar disorder (Munkholm et al., 2013), and schizophrenia (Potvin et al., 2008). Further, findings from the Young Finns Study have demonstrated that polymorphism of IL-6 promoter region is linked to vital exhaustion and atherosclerosis (Chumaeva et al., 2014; Hulkkonen et al., 2009). Consequently, future studies could investigate whether high 
compassion could protect also against a variety of other somatic and psychiatric disorders in individuals coming from risky emotional environments.

Regarding study limitations, we did not have data available to control for the cytokine levels in childhood. Hence, it is possible that in individuals coming from risky emotional family environments, the cytokine levels have been elevated already from childhood onwards. However, the findings most likely refer to the formation of immune system. This is supported by the findings that early adversities may result in a chronic dysregulation of physiological stress systems and inflammatory responses (Shonkoff et al., 2012) and because of the comparatively short half-time of the cytokines. Secondly, we did not have data available on the developmental course of compassion from childhood into adulthood. Consequently, the role of compassion for cytokine levels in different developmental periods and transitions remains to be investigated in the future studies. Furthermore, quantification of cytokines is dependent on which blood component (plasma, serum, or whole blood) is used. Here, we used heparin plasma and heparin that has been demonstrated to cause release of cytokine called eotaxin from cell surface receptors located on erythrocytes (Biancotto et al., 2012). Similar mechanisms might therefore exist for other cytokines as well. This might affect replication of study findings if different blood components are used across studies.

The strengths of this study include the fairly large population-based sample and long-term prospective follow-up over 21 years. Additionally, to our knowledge, this study was the first to investigate the association of early adversities with cytokines in adulthood using a prospective followup from childhood to adulthood and examining a set of different cytokines. A further strength is that the childhood risks and adulthood compassion were reported by different informants reducing the risk for a common method bias. Additionally, we could take into account an array of potential confounders (age, sex, anti-inflammatory drugs, inflammatory diseases, participants' and their parents' socioeconomic factors, body-mass index, health behavior, and depressive symptoms). 
In clinical practice, the findings suggest that there may exist a strong need for antiinflammatory interventions for individuals coming from risky emotional family environments. Previously, it has been emphasized that childhood represents a sensitive period for the establishment of inflammatory responses and, therefore, interventions should be provided as early as possible (e.g. Shonkoff et al., 2012). Our findings provide a hopeful perspective by suggesting that in the presence of high compassion, individuals coming from risky family environments may reach approximately the same cytokine levels than individuals without risky family environment. A review suggested that psychological interventions such as cognitive behavioral therapy and relaxation training may have antiinflammatory influences (Fagundes \& Way, 2012). Our findings suggest that compassion training might be used as an effective intervention against depression-related cytokines in individuals coming from risky emotional family environments.

\section{Data availability statement}

The datasets presented in this article are not readily available because YFS is an ongoing follow-up study and the datasets are not anonymised, and the GDPR prevents public sharing of the data. Instead, pseudonymised datasets are possible to share on request, and requires a data sharing agreement between the parties. Requests to access the datasets should be directed to Liisa Keltikangas-Järvinen (liisa.keltikangas-jarvinen@helsinki.fi) (psychological data) or Sirpa Jalkanen (sirjal@utu.fi) (cytokine data).

\section{Author Contributions}

L.K.-J., T.L., O.R., S.J., and M.H. contributed to data collection. A.S. conducted the statistical analyses and drafted the manuscript. H.D., A.A.-O., M.S., S.J., and M.H. assisted with the statistical analyses. 
A.S., L.K.-J., H.D., A.A.-O., M.S., T.L., O.R., S.J., and M.H. contributed to the interpretation of the results and contributed to writing of the manuscript.

\section{References}

Abelson, J. L., Erickson, T. M., Mayer, S. E., Crocker, J., Briggs, H., Lopez-Duran, N. L., \& Liberzon, I. (2014). Brief cognitive intervention can modulate neuroendocrine stress responses to the Trier Social Stress Test: Buffering effects of a compassionate goal orientation.

Psychoneuroendocrinology, 44, 60-70.

Ahola-Olli, A. V., Würtz, P., Havulinna, A. S., Aalto, K., Pitkänen, N., Lehtimäki, T., ... \& Sarin, A. P. (2017). Genome-wide association study identifies 27 loci influencing concentrations of circulating cytokines and growth factors. Am J Hum Genet, 100, 40-50.

Appleton, A. A., Buka, S. L., McCormick, M. C., Koenen, K. C., Loucks, E. B., \& Kubzansky, L. D. (2012). The association between childhood emotional functioning and adulthood inflammation is modified by early-life socioeconomic status. Health Psychol, 31, 413.

Baldwin, J. R., Arseneault, L., Caspi, A., Fisher, H. L., Moffitt, T. E., Odgers, C. L., ... \& Matthews, T. (2018). Childhood victimization and inflammation in young adulthood: A genetically sensitive cohort study. Brain Behav Immun, 67, 211-217.

Barnard, L. K., \& Curry, J. F. (2011). Self-compassion: Conceptualizations, correlates, \& interventions. Rev Gen Psychol, 15, 289-303.

Baumeister, D., Akhtar, R., Ciufolini, S., Pariante, C. M., \& Mondelli, V. (2016). Childhood trauma and adulthood inflammation: a meta-analysis of peripheral C-reactive protein, interleukin-6 and tumour necrosis factor- $\alpha$. Mol Psychiatry, 21, 642-649. 
Beck, A. T., Steer, R. A., \& Brown, G. K. (1996). Beck depression inventory-II. San Antonio, 78, 490-498.

Biancotto, A., Feng, X., Langweiler, M., Young, N. S., \& McCoy, J. P. (2012). Effect of anticoagulants on multiplexed measurement of cytokine/chemokines in healthy subjects. Cytokine, 60, 438-446.

Black, P. H. (2002). Stress and the inflammatory response: a review of neurogenic inflammation. Brain Behav Immun, 16, 622-653.

Byrne, M. L., Badcock, P. B., Simmons, J. G., Whittle, S., Pettitt, A., Olsson, C. A., ... \& Allen, N. B. (2017). Self-reported parenting style is associated with children's inflammation and immune activation. J Fam Psychol, 31, 374.

Carpenter, L. L., Gawuga, C. E., Tyrka, A. R., Lee, J. K., Anderson, G. M., \& Price, L. H. (2010). Association between plasma IL-6 response to acute stress and early-life adversity in healthy adults. Neuropsychopharmacology, 35, 2617.

Chumaeva, N., Hintsanen, M., Pulkki-Råback, L., Jokela, M., Juonala, M., Lehtimäki, T., ... \& Keltikangas-Järvinen, L. (2014). Interleukin-6 gene polymorphism, chronic stress and atherosclerosis: interleukin-6-174G $>$ C polymorphism, chronic stress and risk of early atherosclerosis in the Cardiovascular Risk in Young Finns Study. J Psychosom Res, 76, 333-338.

Cloninger, C. R., Przybeck, T. R., \& Švrakić, D. M. (1994). The Temperament and Character Inventory (TCI): A guide to its development and use. St. Louis, MO: Center for Psychobiology of Personality, Washington.

Coelho, R., Viola, T. W., Walss-Bass, C., Brietzke, E., \& Grassi-Oliveira, R. (2014). Childhood maltreatment and inflammatory markers: a systematic review. Acta Psychiatr Scand, 129, 180-192. 
Colodro-Conde, L., Couvy-Duchesne, B., Zhu, G., Coventry, W. L., Byrne, E. M., Gordon, S., ... \& Eaves, L. J. (2018). A direct test of the diathesis-stress model for depression. Mol Psychiatry, 23, $1590-1596$.

Coussens, L. M., \& Werb, Z. (2002). Inflammation and cancer. Nature, 420, 860-867.

Danese, A., Pariante, C. M., Caspi, A., Taylor, A., \& Poulton, R. (2007). Childhood maltreatment predicts adult inflammation in a life-course study. Proc Natl Acad Sci USA, 104, 1319-1324.

Do Prado, C. H., Narahari, T., Holland, F. H., Lee, H. N., Murthy, S. K., \& Brenhouse, H. C. (2016). Effects of early adolescent environmental enrichment on cognitive dysfunction, prefrontal cortex development, and inflammatory cytokines after early life stress. Dev Psychobiol, 58, 482-491.

Dowlati, Y., Herrmann, N., Swardfager, W., Liu, H., Sham, L., Reim, E. K., \& Lanctôt, K. L. (2010). A meta-analysis of cytokines in major depression. Biol Psychiatry, 67, 446-457.

Elovainio, M., Keltikangas-Järvinen, L., Kivimäki, M., Pulkki, L., Puttonen, S., Heponiemi, T., ... \& Raitakari, O. T. (2005). Depressive symptoms and carotid artery intima-media thickness in young adults: the Cardiovascular Risk in Young Finns Study. Psychosom Med, 67, 561-567.

Eyre, H. A., Air, T., Proctor, S., Rositano, S., \& Baune, B. T. (2015). A critical review of the efficacy of non-steroidal anti-inflammatory drugs in depression. Prog Neuropsychopharmacol Biol Psychiatry, 57, 11-16.

Fagundes, C. P., \& Way, B. (2014). Early-life stress and adult inflammation. Curr Dir Psychol Sci, 23, $277-283$.

Fond, G., Hamdani, N., Kapczinski, F., Boukouaci, W., Drancourt, N., Dargel, A., ... \& Leboyer, M. (2014). Effectiveness and tolerance of anti-inflammatory drugs' add-on therapy in major mental disorders: a systematic qualitative review. Acta Psychiatr Scand, 129, 163-179. 
Gluschkoff, K., Keltikangas-Järvinen, L., Pulkki-Råback, L., Jokela, M., Viikari, J., Raitakari, O., \& Hintsanen, M. (2017). Hostile parenting, parental psychopathology, and depressive symptoms in the offspring: A 32-year follow-up in the Young Finns study. J Aff Disord, 208, 436-442.

Goetz, J. L., Keltner, D., \& Simon-Thomas, E. (2010). Compassion: an evolutionary analysis and empirical review. Psychol Bull, 136, 351-374.

Hayley, S. (2011). Toward an anti-inflammatory strategy for depression. Front Behav Neurosci, 5, 19. https://doi.org/10.3389/fnbeh.2011.00019

Hermanto, N., Zuroff, D. C., Kopala-Sibley, D. C., Kelly, A. C., Matos, M., Gilbert, P., \& Koestner, R. (2016). Ability to receive compassion from others buffers the depressogenic effect of self-criticism: A cross-cultural multi-study analysis. Pers Individ Dif, 98, 324-332.

Hintsanen, M., Gluschkoff, K., Dobewall, H., Cloninger, C. R., Keltner, D., Saarinen, A., ... \& PulkkiRåback, L. (2019). Parent-child-relationship quality predicts offspring dispositional compassion in adulthood: A prospective follow-up study over three decades. Dev Psychol, 55, 216-225.

Hirvensalo, M., Magnussen, C. G., Yang, X., Telama, R., Heinonen, I., Hutri-Kähönen, N., ... \& Tammelin, T. H. (2017). Convergent validity of a physical activity questionnaire against objectively measured physical activity in adults: The Cardiovascular Risk in Young Finns Study. Advances in Physical Education, 7, 80494.

Hulkkonen, J., Lehtimäki, T., Mononen, N., Juonala, M., Hutri-Kähönen, N., Taittonen, L., ... \& Kähönen, M. (2009). Polymorphism in the IL6 promoter region is associated with the risk factors and markers of subclinical atherosclerosis in men: The Cardiovascular Risk in Young Finns Study. Atherosclerosis, 203, 454-458.

Immordino-Yang, M. H., McColl, A., Damasio, H., \& Damasio, A. (2009). Neural correlates of admiration and compassion. Proc Natl Acad Sci, 106, 8021-8026. 
Jazaieri, H., Jinpa, G. T., McGonigal, K., Rosenberg, E. L., Finkelstein, J., Simon-Thomas, E., Cullen, M., Doty, J. R., Gross, J. J., \& Goldin, P. R. (2013). Enhancing compassion: a randomized controlled trial of a compassion cultivation training program. Journal of Happiness Studies, 14, 1113-1126.

Jiang, H. K., \& Chang, D. M. (1999). Non-steroidal anti-inflammatory drugs with adverse psychiatric reactions: five case reports. Clinical Rheumatology, 18, 339-345.

Kelly, A. C., \& Dupasquier, J. (2016). Social safeness mediates the relationship between recalled parental warmth and the capacity for self-compassion and receiving compassion. Pers Individ Dif, 89, 157-161.

Kiecolt-Glaser, J. K., Gouin, J. P., Weng, N. P., Malarkey, W. B., Beversdorf, D. Q., \& Glaser, R. (2011). Childhood adversity heightens the impact of later-life caregiving stress on telomere length and inflammation. Psychosom Med, 73, 16.

Kim, J. J., Parker, S. L., Doty, J. R., Cunnington, R., Gilbert, P., \& Kirby, J. N. (2020). Neurophysiological and behavioural markers of compassion. Sci Rep, 10, 1-9.

Kirby, J. N., Day, J., \& Sagar, V. (2019). The 'Flow'of compassion: A meta-analysis of the fears of compassion scales and psychological functioning. Clin Psychol Rev, 70, 26-39.

Kirby, J. N., Tellegen, C. L., \& Steindl, S. R. (2017). A meta-analysis of compassion-based interventions: Current state of knowledge and future directions. Behavior Therapy, 48, 778-792.

Kuhlman, K. R., Horn, S. R., Chiang, J. J., \& Bower, J. E. (2020). Early life adversity exposure and circulating markers of inflammation in children and adolescents: A systematic review and metaanalysis. Brain Behav Immun, 86, 30-42.

Köhler, O., Benros, M. E., Nordentoft, M., Farkouh, M. E., Iyengar, R. L., Mors, O., \& Krogh, J. (2014). Effect of anti-inflammatory treatment on depression, depressive symptoms, and adverse effects: a systematic review and meta-analysis of randomized clinical trials. JAMA Psychiatry, 71, 1381-1391. 
Lindahl, B., Toss, H., Siegbahn, A., Venge, P., \& Wallentin, L. (2000). Markers of myocardial damage and inflammation in relation to long-term mortality in unstable coronary artery disease. $N$ Engl $J$ Med, 343, 1139-1147.

Matos, M., Duarte, J., \& Pinto-Gouveia, J. (2017). The origins of fears of compassion: Shame and lack of safeness memories, fears of compassion and psychopathology. $J$ Psychol, 151, 804-819.

McDade, T. W., Ryan, C., Jones, M. J., MacIsaac, J. L., Morin, A. M., Meyer, J. M., ... \& Kuzawa, C. W. (2017). Social and physical environments early in development predict DNA methylation of inflammatory genes in young adulthood. Proc Natl Acad Sci, 114, 7611-7616.

McLaughlin, K. A., Conron, K. J., Koenen, K. C., \& Gilman, S. E. (2010). Childhood adversity, adult stressful life events, and risk of past-year psychiatric disorder: a test of the stress sensitization hypothesis in a population-based sample of adults. Psychol Med, 40, 1647-1658.

Miller, G. E., \& Chen, E. (2010). Harsh family climate in early life presages the emergence of a proinflammatory phenotype in adolescence. Psychol Sci, 21, 848-856.

Mills, N. T., Scott, J. G., Wray, N. R., Cohen-Woods, S., \& Baune, B. T. (2013). Research review: the role of cytokines in depression in adolescents: a systematic review. J Child Psychol Psychiatry, 54, 816-835.

Munkholm, K., Braüner, J. V., Kessing, L. V., \& Vinberg, M. (2013). Cytokines in bipolar disorder vs. healthy control subjects: a systematic review and meta-analysis. $J$ Psychiatr Res, 47, 1119-1133.

Nieminen, A., Maksimow, M., Mentula, P., Kyhälä, L., Kylänpää, L., Puolakkainen, P., ... \& Salmi, M. (2014). Circulating cytokines in predicting development of severe acute pancreatitis. Crit Care, 18, R104. 
Pace, T. W., Negi, L. T., Adame, D. D., Cole, S. P., Sivilli, T. I., Brown, T. D., ... \& Raison, C. L. (2009). Effect of compassion meditation on neuroendocrine, innate immune and behavioral responses to psychosocial stress. Psychoneuroendocrinology, 34, 87-98.

Padgett, D. A., \& Glaser, R. (2003). How stress influences the immune response. Trends in Immunology, 24, 444-448.

Pearson, T. A., Mensah, G. A., Alexander, R. W., Anderson, J. L., Cannon, R. O., Criqui, M., ... \& Rifai, N. (2003). Markers of inflammation and cardiovascular disease. Circulation, 107, 499-511.

Pereira, S. M. P., Merkin, S. S., Seeman, T., \& Power, C. (2019). Understanding associations of earlylife adversities with mid-life inflammatory profiles: Evidence from the UK and USA. Brain Behav Immun, 78, 143-152.

Pietikäinen, A., Maksimow, M., Kauko, T., Hurme, S., Salmi, M., \& Hytönen, J. (2016). Cerebrospinal fluid cytokines in Lyme neuroborreliosis. Journal of neuroinflammation, 13(1), 273.

Potvin, S., Stip, E., Sepehry, A. A., Gendron, A., Bah, R., \& Kouassi, E. (2008). Inflammatory cytokine alterations in schizophrenia: a systematic quantitative review. Biol Psychiatry, 63, 801-808.

Pulkki-Råback, L., Elovainio, M., Hakulinen, C., Lipsanen, J., Hintsanen, M., Jokela, M., ... \& Keltikangas-Järvinen, L. (2015). Cumulative effect of psychosocial factors in youth on ideal cardiovascular health in adulthood: the Cardiovascular Risk in Young Finns Study. Circulation, 131, 245-253.

Raitakari, O. T., Juonala, M., Rönnemaa, T., Keltikangas-Järvinen, L., Räsänen, L., Pietikäinen, M., ..., Jula, A. (2008). Cohort profile: the cardiovascular risk in Young Finns Study. Int J Epidemiol, 37, $1220-1226$.

Reid, B. M., Doom, J. R., Argote, R. B., Correa-Burrows, P., Lozoff, B., Blanco, E., \& Gahagan, S. (2020). Pathways to inflammation in adolescence through early adversity, childhood depressive 
Emotional environment, compassion and cytokines

symptoms, and body mass index: a prospective longitudinal study of Chilean infants. Brain Behav Immun, 86, 4-13.

Rooks, C., Veledar, E., Goldberg, J., Bremner, J. D., \& Vaccarino, V. (2012). Early trauma and inflammation: role of familial factors in a study of twins. Psychosom Med, 74, 146.

Saarinen, A., Keltikangas-Järvinen, L., Cloninger, C. R., Veijola, J., Elovainio, M., Lehtimäki, T., ... \& Hintsanen, M. (2019). The relationship of dispositional compassion for others with depressive symptoms over a 15-year prospective follow-up. J Affect Disord, 250, 354-362.

Saarinen, A. I., Keltikangas-Järvinen, L., Pulkki-Råback, L., Cloninger, C. R., Elovainio, M., Lehtimäki, T., ... \& Hintsanen, M. (2019). The relationship of dispositional compassion with wellbeing: a study with a 15-year prospective follow-up. J Posit Psychol, 1-15.

Santalahti, K., Maksimow, M., Airola, A., Pahikkala, T., Hutri-Kähönen, N., Jalkanen, S., ... \& Salmi, M. (2016). Circulating cytokines predict the development of insulin resistance in a prospective Finnish population cohort. J Clin Endocrinol Metab, 101, 3361-3369.

Santalahti, K., Havulinna, A., Maksimow, M., Zeller, T., Blankenberg, S., Vehtari, A., ... \& Salmi, M. (2017). Plasma levels of hepatocyte growth factor and placental growth factor predict mortality in a general population: a prospective cohort study. J Intern Med, 282, 340-352.

Schmeer, K. K., \& Yoon, A. J. (2016). Home sweet home? Home physical environment and inflammation in children. Soc Sci Res, 60, 236-248.

Shonkoff, J. P., Garner, A. S., Siegel, B. S., Dobbins, M. I., Earls, M. F., McGuinn, L., ... \& Committee on Early Childhood, Adoption, and Dependent Care. (2012). The lifelong effects of early childhood adversity and toxic stress. Pediatrics, 129, e232-e246.

Takizawa, R., Danese, A., Maughan, B., \& Arseneault, L. (2015). Bullying victimization in childhood predicts inflammation and obesity at mid-life: a five-decade birth cohort study. Psychol Med, 45, 2705. 
Tian, R., Hou, G., Li, D., \& Yuan, T. F. (2014). A possible change process of inflammatory cytokines in the prolonged chronic stress and its ultimate implications for health. The Scientific World Journal, 780616.

Tien, P. C., Choi, A. I., Zolopa, A. R., Benson, C., Scherzer, R., Bacchetti, P., ... \& Grunfeld, C. (2010). Inflammation and mortality in HIV-infected adults: analysis of the FRAM study cohort. $J$ Acquir Immune Defic Syndr, 55, 316-322.

Tyrka, A. R., Parade, S. H., Valentine, T. R., Eslinger, N. M., \& Seifer, R. (2015). Adversity in preschoolaged children: Effects on salivary interleukin-1ß. Dev Psychopathol, 27, 567.

Uher, R., Carver, S., Power, R. A., Mors, O., Maier, W., Rietschel, M., ... \& Placentino, A. (2012). Non-steroidal anti-inflammatory drugs and efficacy of antidepressants in major depressive disorder. Psychol Med, 42, 2027-2035.

Wellen, K. E., \& Hotamisligil, G. S. (2005). Inflammation, stress, and diabetes. J Clin Invest, 115, $1111-1119$.

Wållberg-Jonsson, S., Johansson, H., Ohman, M. L., \& Rantapää-Dahlqvist, S. (1999). Extent of inflammation predicts cardiovascular disease and overall mortality in seropositive rheumatoid arthritis. A retrospective cohort study from disease onset. J Rheumatol, 26, 2562-2571.

Yeun, J. Y., Levine, R. A., Mantadilok, V., \& Kaysen, G. A. (2000). C-reactive protein predicts allcause and cardiovascular mortality in hemodialysis patients. Am J Kidney Dis, 35, 469-476.

Young, J. J., Bruno, D., \& Pomara, N. (2014). A review of the relationship between proinflammatory cytokines and major depressive disorder. $J$ Affect Disord, 169, 15-20. 
Emotional environment, compassion and cytokines

Table 1. The means, standard deviations (SD), frequencies, and ranges of the study variables.

\begin{tabular}{llll}
\hline & Mean (SD) & Range & Frequency (\%) \\
\hline Age in 2001 & $31.7(5.0)$ & $24 ; 39$ & \\
Sex (female) & & & $875(57.5)$ \\
$\begin{array}{l}\text { Parents' educational level } \\
\quad \text { Comprehensive school }\end{array}$ & & & $481(31.9)$ \\
$\quad$ High school or occupational school & & & $645(42.7)$ \\
$\quad$ Academic level & & & $384(25.4)$ \\
Parents' level of income & $4.9(1.9)$ & $1 ; 8$ & \\
Participants' educational level & & & $61(4.0)$ \\
$\quad$ Comprehensive school & & & $867(57.0)$ \\
$\quad$ High school or occupational school & & & \\
$\quad$ Academic level & $3.5(1.5)$ & $1 ; 8$ & \\
Participants' level of income & $25.8(4.6)$ & $16.6 ; 58.8$ & \\
Body-mass index & $2.1(1.5)$ & $1 ; 5$ & \\
Smoking & $2.0(0.6)$ & $1 ; 5$ & \\
Alcohol use & $2.4(1.4)$ & $1 ; 6$ & \\
Alcohol intoxication & & &
\end{tabular}




\begin{tabular}{llll}
$\begin{array}{l}\text { Depressive symptoms } \\
\text { Use of anti-inflammatory drugs }\end{array}$ & $2.0(0.7)$ & $1 ; 5$ & $46(3.0)$ \\
$\begin{array}{l}\text { Inflammatory disease } \\
\text { Emotional environment score }\end{array}$ & $0.5(0.7)$ & & $64(4.2)$ \\
Compassion & $3.7(0.6)$ & $0 ; 4$ & \\
Cytokines (pg/ml $)^{1}$ & & $1 ; 5$ \\
IL-2 & $26(101)$ & $0 ; 2452$ \\
IL-6 & $16(57)$ & $4 ; 2049$ \\
IL-1b & $5(2)$ & $0 ; 32$ \\
MCP-1 & $36(23)$ & $8 ; 676$ \\
IFN- $\gamma$ & $288(226)$ & $74 ; 6271$ \\
TNF- $\alpha$ & $65(231)$ & $15 ; 8434$ \\
\hline
\end{tabular}

Note: In the analyses, we used logarithm-transformed variables of the cytokines. 
Emotional environment, compassion and cytokines

Table 2. The results of the linear regression analyses, when predicting the logarithm-transformed cytokine levels in 2007 by risky emotional family environment in 1980.

\begin{tabular}{|c|c|c|c|c|c|c|}
\hline & \multicolumn{3}{|c|}{ Model $1(\mathrm{~N}=1523)$} & \multicolumn{3}{|c|}{ Model $2(\mathrm{~N}=1198)$} \\
\hline & $\mathrm{B}$ & $95 \% \mathrm{CI}$ & $\mathrm{p}$ & $\mathrm{B}$ & $95 \% \mathrm{CI}$ & $\mathrm{p}$ \\
\hline \multicolumn{7}{|c|}{ Risky family environment } \\
\hline IL-2 & 0.046 & $0.015 ; 0.077$ & 0.004 & 0.045 & $0.008 ; 0.081$ & 0.016 \\
\hline IL-6 & 0.048 & $0.019 ; 0.079$ & 0.001 & 0.049 & $0.013 ; 0.084$ & 0.007 \\
\hline IL-1b & 0.014 & $-0.007 ; 0.035$ & 0.194 & 0.012 & $-0.013 ; 0.037$ & 0.338 \\
\hline MCP-1 & 0.005 & $-0.020 ; 0.029$ & 0.711 & 0.002 & $-0.026 ; 0.030$ & 0.875 \\
\hline IFN- $\gamma$ & 0.026 & $0.005 ; 0.048$ & 0.014 & 0.033 & $0.008 ; 0.057$ & 0.010 \\
\hline $\mathrm{TNF}-\alpha$ & 0.039 & $0.008 ; 0.070$ & 0.013 & 0.043 & $0.007 ; 0.079$ & 0.021 \\
\hline
\end{tabular}

$* p<.05 * * p<.01 * * * p<.001$

Model 1: Adjusted for age, sex, the use of anti-inflammatory medications, and inflammatory diseases.

Model 2: Adjusted also for socioeconomic factors in childhood and adulthood, body-mass index, health behavior (smoking, alcohol use, alcohol intoxication, and physical activity), and depressive symptoms.

Note: All the cytokines were set as outcome variables simultaneously. 
Emotional environment, compassion and cytokines

Table 3. The results of the fully-adjusted multivariate regression analyses, when predicting the logarithm-transformed cytokine levels in 2007 by risky emotional family environment in 1980 and compassion in 2001.

\begin{tabular}{|c|c|c|c|c|c|c|}
\hline & \multicolumn{3}{|c|}{ Model $1(\mathrm{~N}=1523)$} & \multicolumn{3}{|c|}{ Model $2(\mathrm{~N}=1198)$} \\
\hline & $\mathrm{B}$ & $95 \% \mathrm{CI}$ & $\mathrm{p}$ & $\mathrm{B}$ & $95 \% \mathrm{CI}$ & $\mathrm{p}$ \\
\hline \multicolumn{7}{|l|}{ IL-2 } \\
\hline Risky family environment & 0.273 & $0.096 ; 0.452$ & 0.003 & 0.352 & $0.145 ; 0.558$ & 0.001 \\
\hline Compassion & 0.032 & $-0.010 ; 0.074$ & 0.131 & 0.037 & $-0.014 ; 0.087$ & 0.156 \\
\hline Risky family environment*Compassion & -0.062 & $-0.110 ;-0.015$ & 0.011 & -0.084 & $-0.140 ;-0.028$ & 0.003 \\
\hline \multicolumn{7}{|l|}{ IL-6 } \\
\hline Risky family environment & 0.242 & $0.072 ; 0.413$ & 0.005 & 0.353 & $0.153 ; 0.553$ & 0.001 \\
\hline Compassion & 0.025 & $-0.015 ; 0.065$ & 0.220 & 0.043 & $-0.007 ; 0.092$ & 0.090 \\
\hline Risky family environment*Compassion & -0.053 & $-0.099 ;-0.007$ & 0.024 & -0.083 & $-0.138 ;-0.029$ & 0.003 \\
\hline \multicolumn{7}{|l|}{$\mathrm{IL}-1 \mathrm{~b}$} \\
\hline Risky family environment & 0.111 & $-0.012 ; 0.234$ & 0.076 & 0.098 & $-0.043 ; 0.239$ & 0.174 \\
\hline Compassion & 0.019 & $-0.009 ; 0.048$ & 0.187 & 0.017 & $-0.017 ; 0.052$ & 0.324 \\
\hline Risky family environment ${ }^{*}$ Compassion & -0.026 & $-0.059 ; 0.007$ & 0.116 & -0.024 & $-0.062 ; 0.015$ & 0.226 \\
\hline \multicolumn{7}{|l|}{ MCP-1 } \\
\hline Risky family environment & 0.063 & $-0.077 ; 0.204$ & 0.377 & 0.128 & $-0.032 ; 0.289$ & 0.118 \\
\hline Compassion & 0.004 & $-0.029 ; 0.037$ & 0.821 & 0.022 & $-0.017 ; 0.062$ & 0.265 \\
\hline Risky family environment*Compassion & -0.016 & $-0.054 ; 0.022$ & 0.405 & -0.035 & $-0.078 ; 0.009$ & 0.118 \\
\hline \multicolumn{7}{|l|}{ IFN- $\gamma$} \\
\hline Risky family environment & 0.145 & $0.023 ; 0.267$ & 0.020 & 0.167 & $0.026 ; 0.308$ & 0.020 \\
\hline Compassion & 0.018 & $-0.011 ; 0.046$ & 0.054 & 0.025 & $-0.010 ; 0.059$ & 0.160 \\
\hline Risky family environment*Compassion & -0.032 & $-0.065 ; 0.000$ & 0.054 & -0.037 & $-0.075 ; 0.001$ & 0.058 \\
\hline \multicolumn{7}{|l|}{ TNF- $\alpha$} \\
\hline Risky family environment & 0.267 & $0.089 ; 0.445$ & 0.003 & 0.353 & $0.146 ; 0.559$ & 0.001 \\
\hline Compassion & 0.038 & $-0.004 ; 0.080$ & 0.077 & 0.051 & $0.000 ; 0.102$ & 0.049 \\
\hline Risky family environment*Compassion & -0.062 & $-0.110 ;-0.014$ & 0.011 & -0.085 & $-0.141 ;-0.029$ & 0.003 \\
\hline
\end{tabular}

$* p<.05 * * p<.01 * * * p<.001$

Model 1: Adjusted for age, sex, the use of anti-inflammatory medications, and inflammatory diseases.

Model 2: Adjusted also for socioeconomic factors in childhood and adulthood, body-mass index, health behavior (smoking, alcohol use, alcohol intoxication, and physical activity), and depressive symptoms.

Note: All the cytokines were set as outcome variables simultaneously. 
(a)

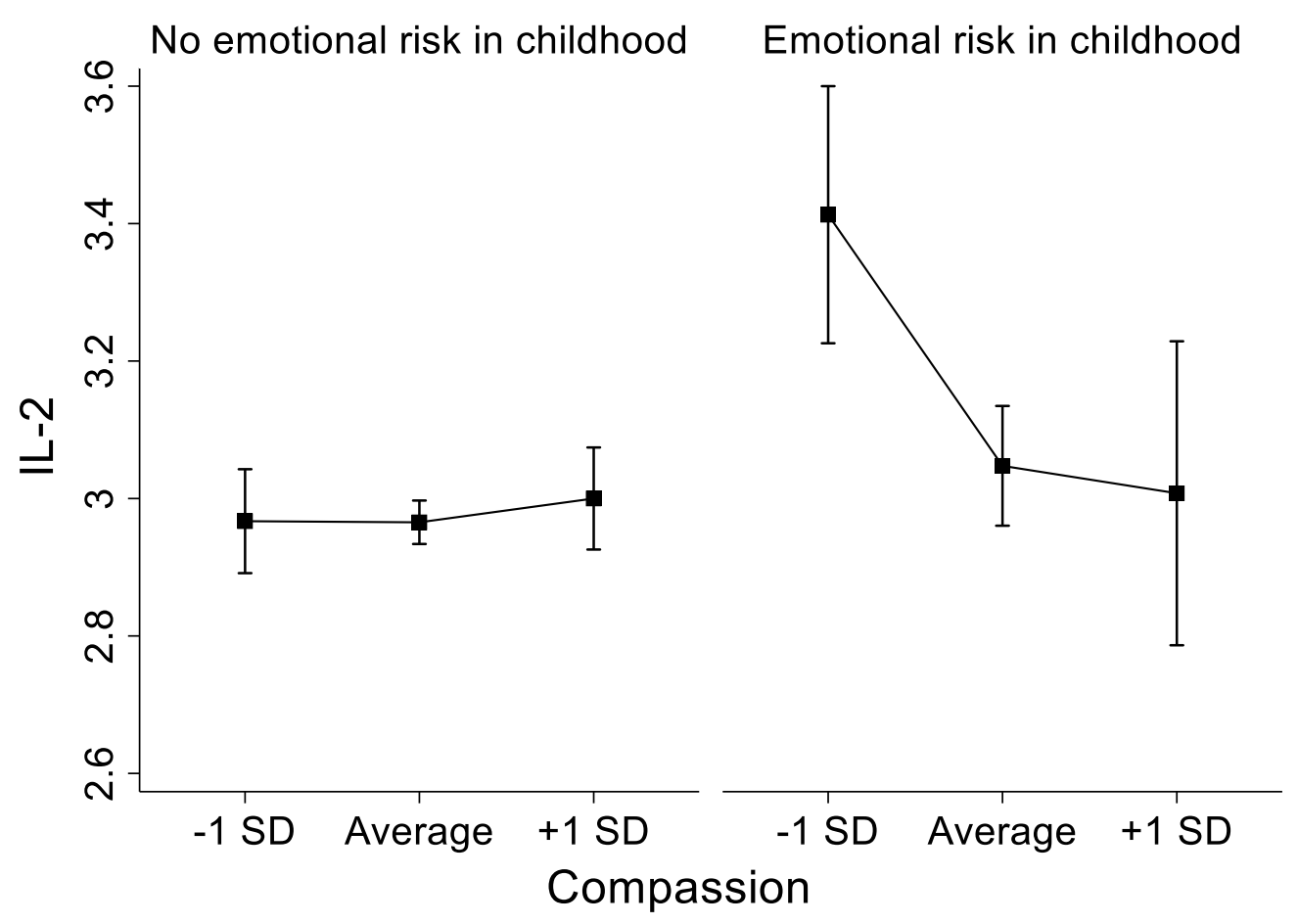

(b)

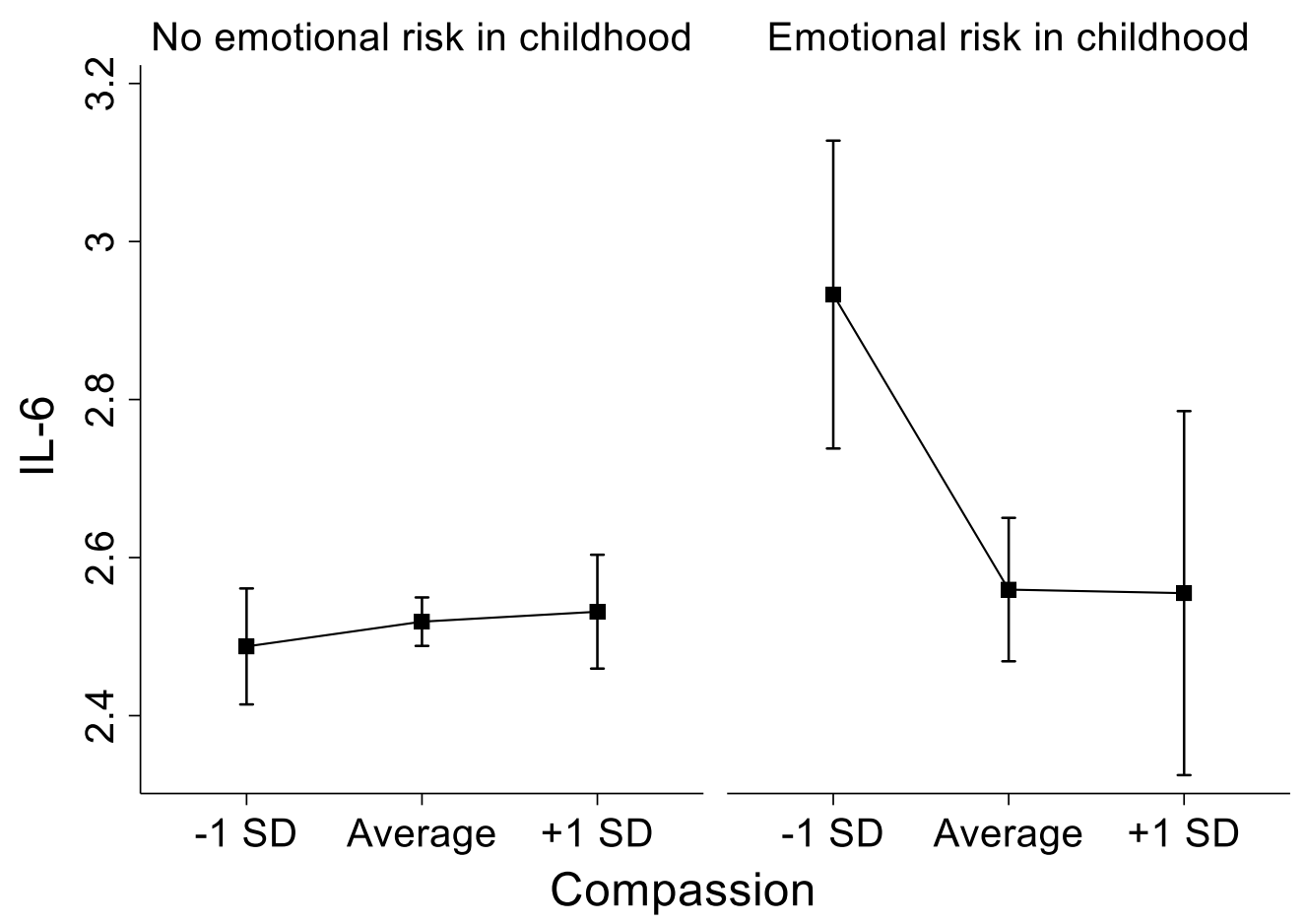


(c)

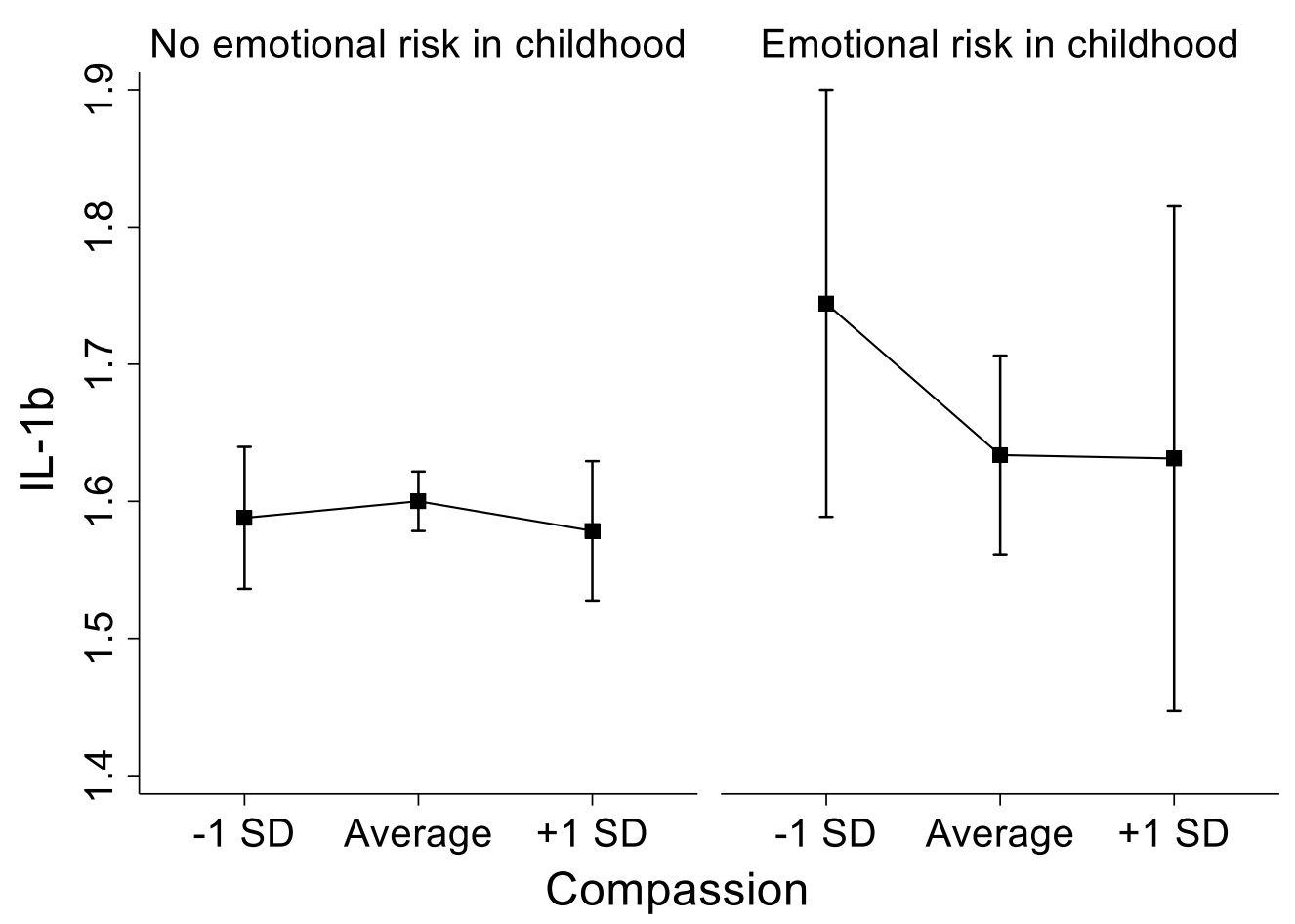

(d)

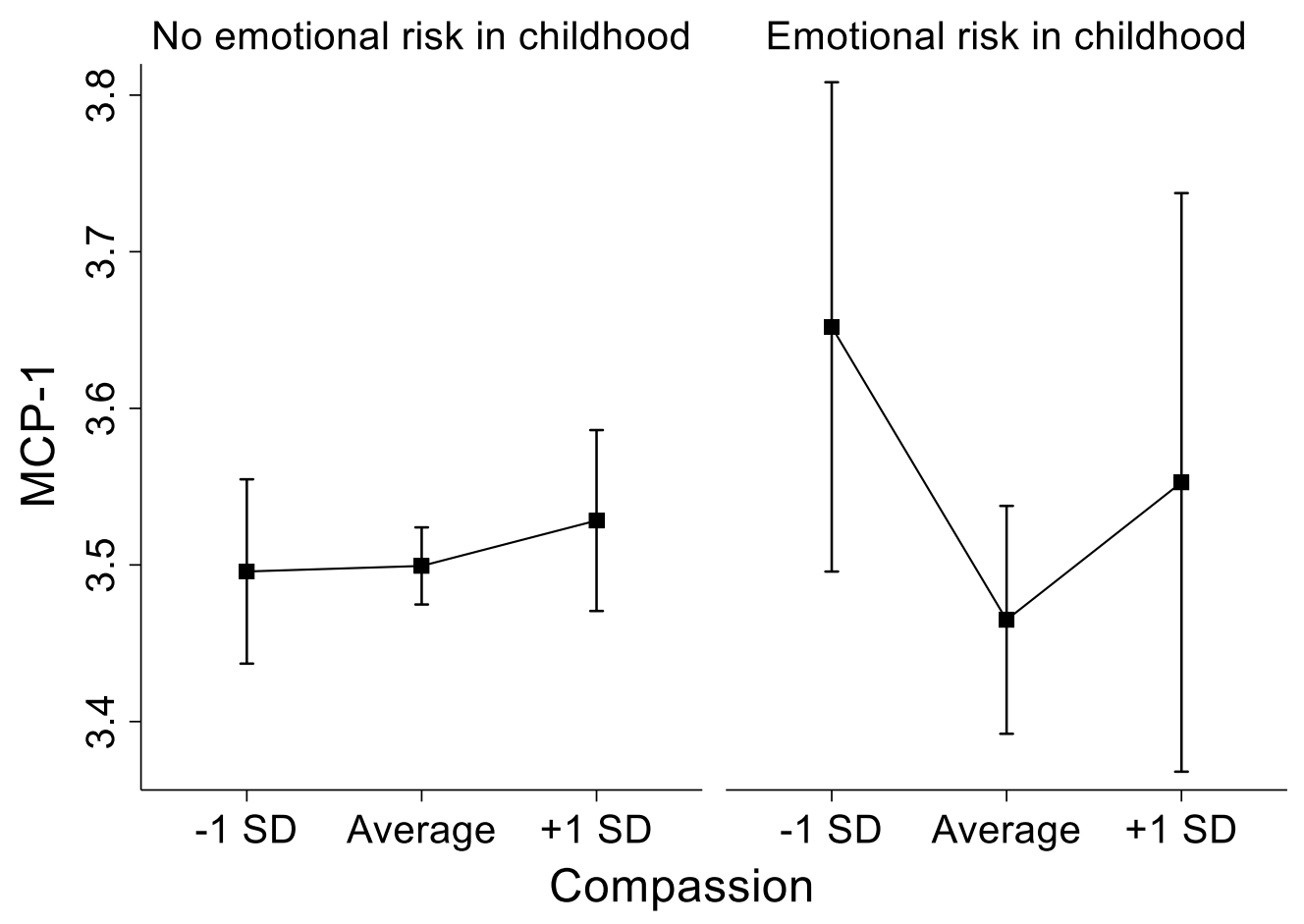


(e)

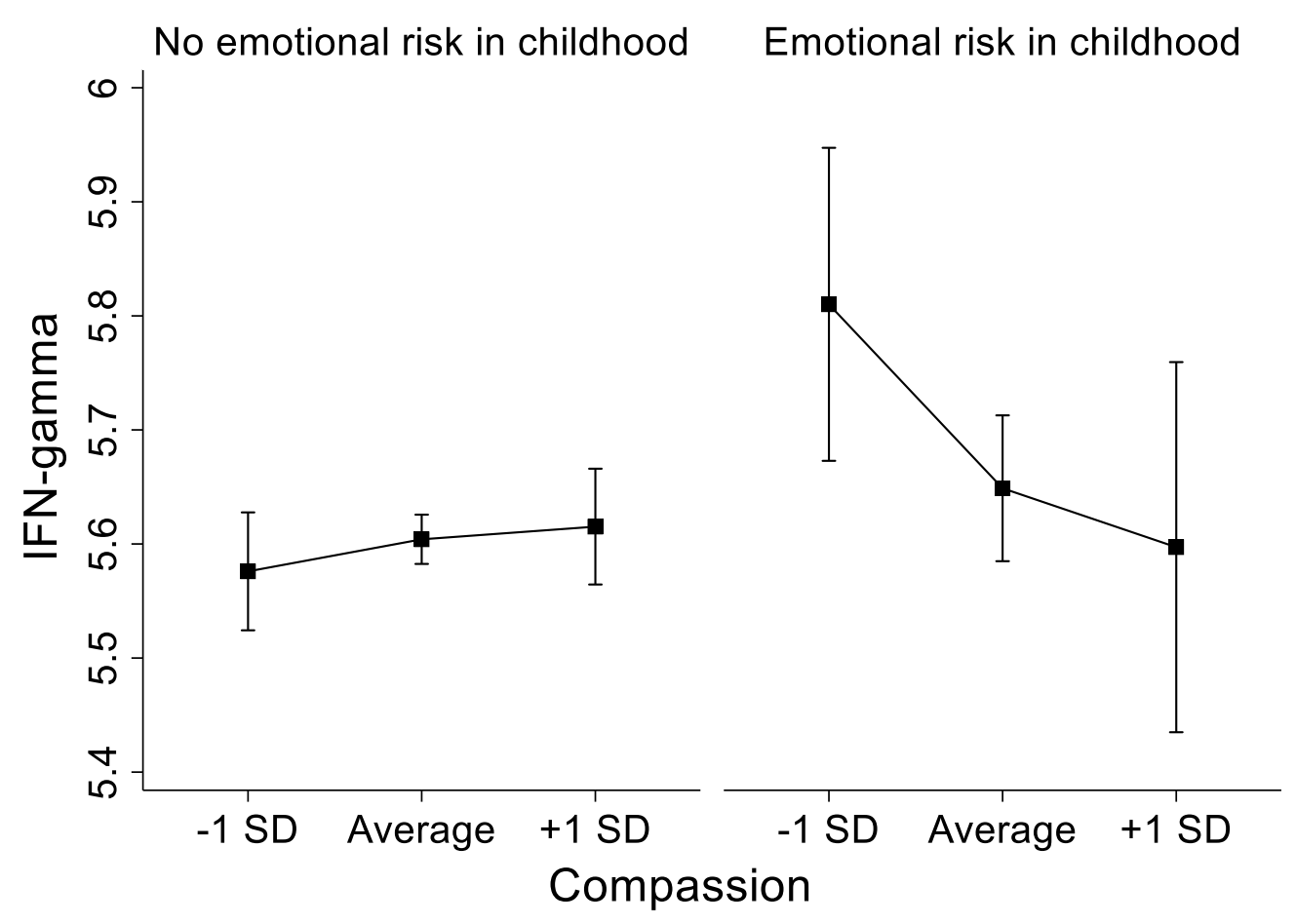

(f)

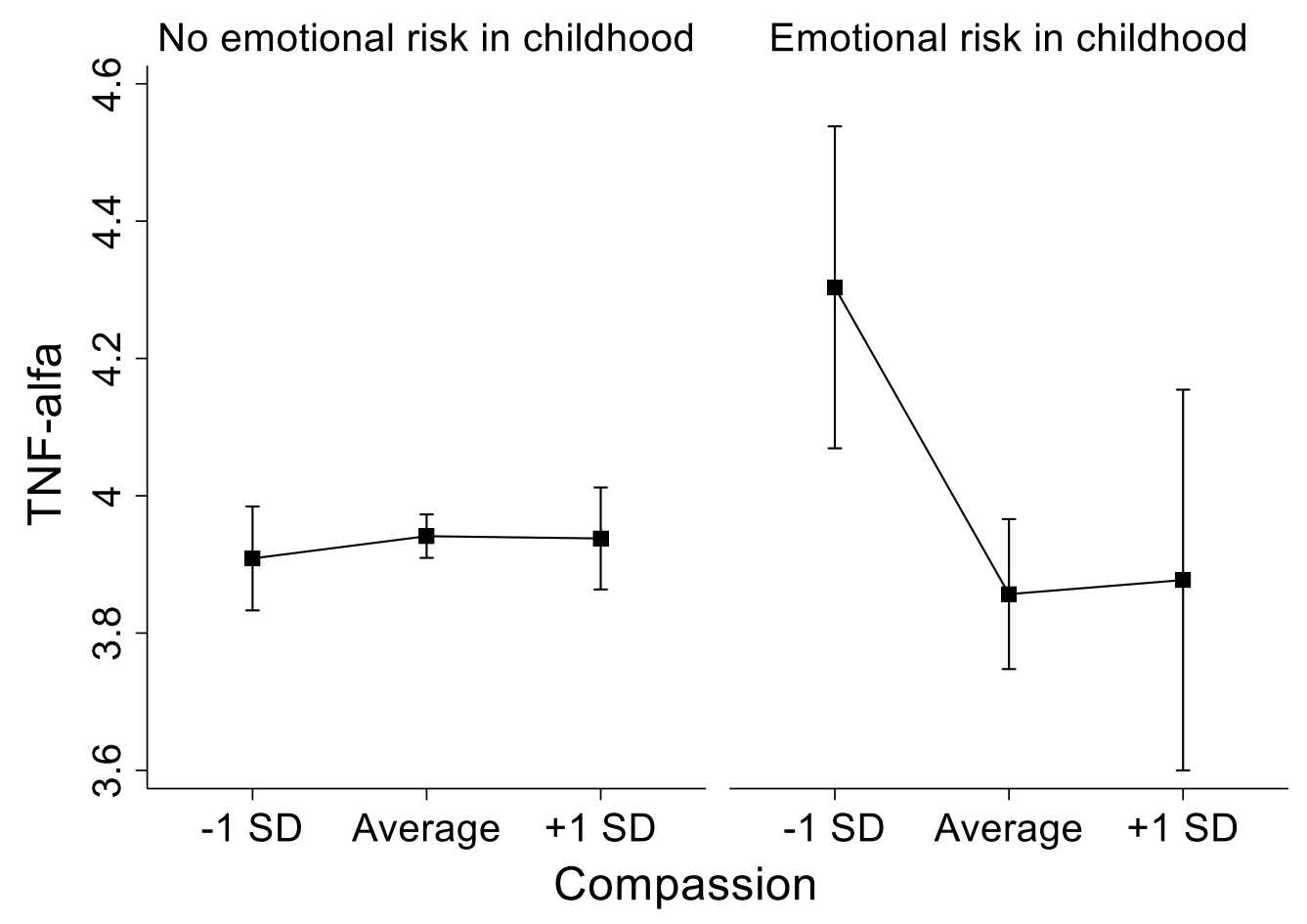


Figure 1. The logarithm-transformed levels of (a) IL-2, (b) IL-6, (c) IL-1b, (d) MCP-1 (e) IFN- $\gamma$, (f) TNF- $\alpha$ separately for individuals with $(\mathrm{N}=154)$ and without $(\mathrm{N}=1369)$ risky emotional family environment in childhood and with different levels of compassion (-1 SD=below one standard deviation; $+1 \mathrm{SD}=$ above one standard deviation; Average $=$ others). Note: Adjusted for age, sex, socioeconomic factors in childhood and adulthood, participants' BMI, health behavior (smoking, alcohol use, alcohol intoxication, physical activity), depressive symptoms, the use of anti-inflammatory medications, and inflammatory diseases. 


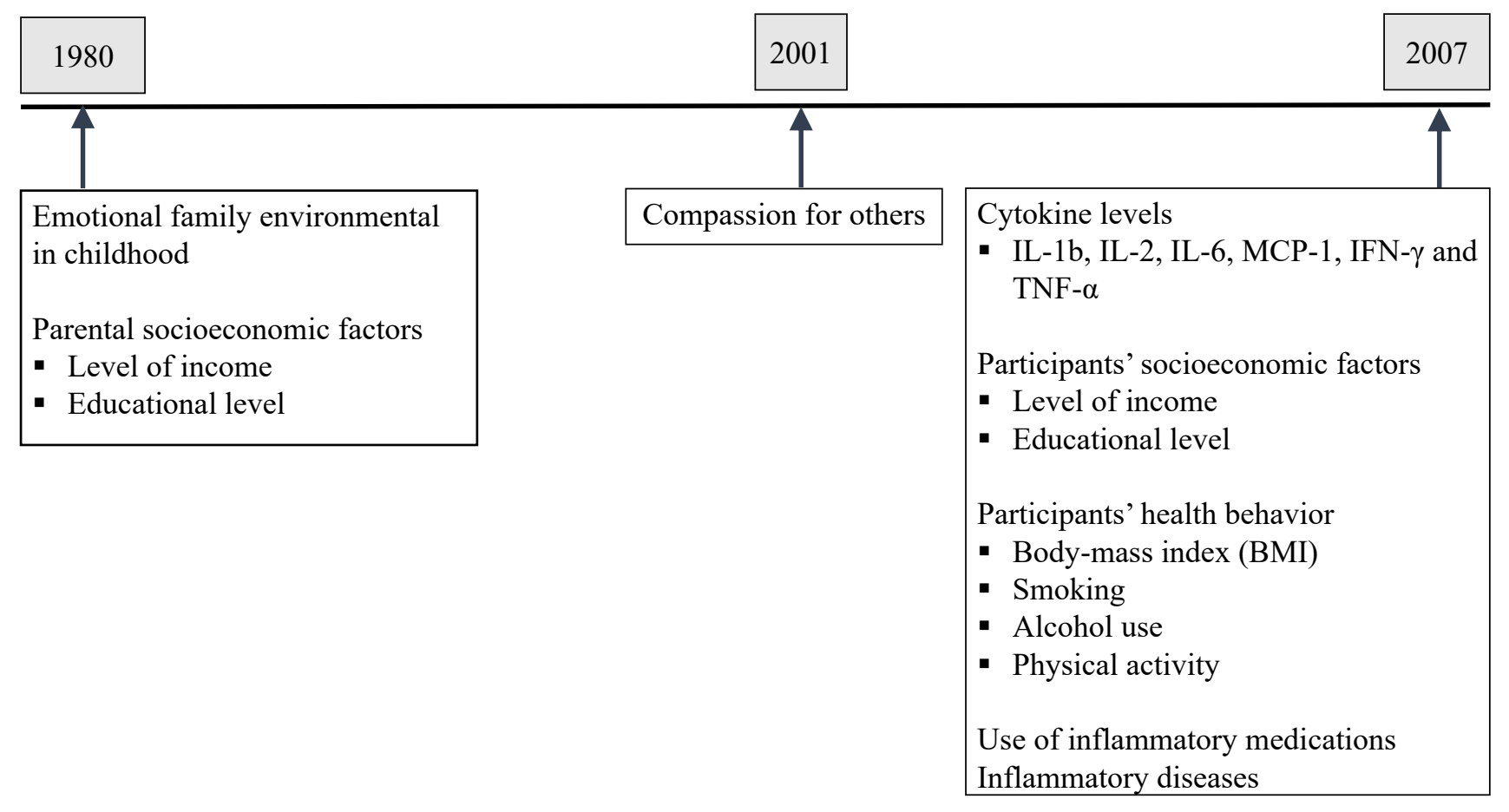

Supplementary Figure 1. The study design. 
Supplementary Material. The 5-item scale of physical activity.

(i) "How often do you engage in sport or physical activity so that you get out of breath and sweat?" ( $1=$ never or once a month; $2=1-6$ times per week; $3=$ daily $)$

(ii) "How much breathlessness and sweating do you experience when you engage in sport or physical activity?" $(1=$ not at all; $3=\mathrm{a}$ lot $)$

(iii) "How much time do you usually spend in one session of sport of physical activity?" (1=less than 20 minutes; $4=$ =more than 60 minutes)

(iv) "How many hours per week do you usually engage in sport or physical activity so that you get out of breath and sweat?" ( $1=1$ hour or less; $2=2-6$ hours; $3=7$ hours or more)

(v) "Do you participate in organized physical activity (e.g. in sport club)?" (1=not at all; 2=yes, regularly about one hour per week; $3=$ several hours per week). 
Supplementary Table 1. The results of the fully-adjusted structural equation models with fullinformation maximum likelihood estimation, when predicting the logarithm-transformed cytokine levels in 2007 by risky emotional family environment in 1980 and compassion in 2001.

\begin{tabular}{llll}
\hline & $\mathrm{B}$ & $95 \% \mathrm{CI}$ & $\mathrm{p}$ \\
\hline IL-2 & & & \\
$\quad$ Risky family environment & 0.414 & $0.125 ; 0.704$ & 0.005 \\
$\quad$ Compassion & 0.046 & $-0.017 ; 0.109$ & 0.155 \\
$\quad$ Risky family environment*Compassion & -0.377 & $-0.669 ;-0.085$ & 0.011 \\
IL-6 & & & \\
Risky family environment & 0.385 & $0.098 ; 0.673$ & 0.009 \\
Compassion & 0.045 & $-0.017 ; 0.108$ & 0.155 \\
Risky family environment*Compassion & -0.346 & $-0.636 ;-0.055$ & 0.020 \\
IL-1b & & & \\
Risky family environment & 0.243 & $-0.055 ; 0.540$ & 0.110 \\
Compassion & 0.038 & $-0.027 ; 0.103$ & 0.248 \\
Risky family environment*Compassion & -0.242 & $-0.543 ; 0.058$ & 0.114 \\
MCP-1 & & & \\
Risky family environment & 0.163 & $-0.123 ; 0.449$ & 0.264 \\
Compassion & 0.027 & $-0.035 ; 0.089$ & 0.402 \\
$\quad$ Risky family environment*Compassion & -0.167 & $-0.456 ; 0.121$ & 0.256 \\
IFN- $\gamma$ & & & \\
Risky family environment & 0.342 & $0.058 ; 0.627$ & 0.018 \\
Compassion & 0.051 & $-0.011 ; 0.113$ & 0.106 \\
Risky family environment*Compassion & -0.308 & $-0.585 ;-0.021$ & 0.036 \\
TNF- $\alpha$ & & & \\
Risky family environment & 0.454 & $0.157 ; 0.751$ & 0.003 \\
Compassion & 0.062 & $-0.003 ; 0.126$ & 0.061 \\
Risky family environment*Compassion & -0.427 & $-0.727 ;-0.127$ & 0.005 \\
\hline
\end{tabular}

$* p<.05 * * p<.01 * * * p<.001 N=2163$

The model was adjusted for age, sex, the use of anti-inflammatory medications, inflammatory diseases, socioeconomic factors in childhood and adulthood, body-mass index, and health behavior (smoking, alcohol use, alcohol intoxication, and physical activity).

Note: All the cytokines were set as outcome variables simultaneously. 
Emotional environment, compassion and cytokines

Supplementary Table 2. The results of the multivariate multiple regression analyses, when predicting the logarithm-transformed cytokine levels in 2007 by risky emotional family environment in 1980 and compassion in 2001 and not controlling for depressive symptoms.

\begin{tabular}{|c|c|c|c|c|c|c|}
\hline & \multicolumn{3}{|c|}{ Model $1(\mathrm{~N}=1337)$} & \multicolumn{3}{|c|}{ Model $2(\mathrm{~N}=1337)$} \\
\hline & $\mathrm{B}$ & $95 \% \mathrm{CI}$ & $\mathrm{p}$ & $\mathrm{B}$ & $95 \% \mathrm{CI}$ & $\mathrm{p}$ \\
\hline \multicolumn{7}{|l|}{ IL-2 } \\
\hline Risky family environment & 0.046 & $0.013 ; 0.08$ & 0.006 & 0.248 & $0.055 ; 0.44$ & 0.012 \\
\hline Compassion & & & & 0.029 & $-0.017 ; 0.076$ & 0.220 \\
\hline Risky family environment*Compassion & & & & -0.055 & $-0.107 ;-0.003$ & 0.038 \\
\hline \multicolumn{7}{|l|}{ IL-6 } \\
\hline Risky family environment & 0.044 & $0.012 ; 0.076$ & 0.007 & 0.246 & $0.062 ; 0.430$ & 0.009 \\
\hline Compassion & & & & 0.035 & $-0.010 ; 0.079$ & 0.124 \\
\hline Risky family environment*Compassion & & & & -0.055 & $-0.105 ;-0.006$ & 0.029 \\
\hline \multicolumn{7}{|l|}{ IL-1b } \\
\hline Risky family environment & 0.010 & $-0.013 ; 0.032$ & 0.387 & 0.065 & $-0.067 ; 0.196$ & 0.336 \\
\hline Compassion & & & & 0.018 & $-0.014 ; 0.049$ & 0.277 \\
\hline Risky family environment*Compassion & & & & -0.015 & $-0.050 ; 0.021$ & 0.410 \\
\hline \multicolumn{7}{|l|}{ MCP-1 } \\
\hline Risky family environment & 0.005 & $-0.021 ; 0.031$ & 0.714 & 0.061 & $-0.090 ; 0.212$ & 0.431 \\
\hline Compassion & & & & 0.015 & $-0.022 ; 0.051$ & 0.433 \\
\hline Risky family environment*Compassion & & & & -0.015 & $-0.056 ; 0.025$ & 0.462 \\
\hline \multicolumn{7}{|l|}{ IFN- $\gamma$} \\
\hline Risky family environment & 0.026 & $0.003 ; 0.048$ & 0.026 & 0.141 & $0.010 ; 0.271$ & 0.034 \\
\hline Compassion & & & & 0.028 & $-0.004 ; 0.059$ & 0.083 \\
\hline Risky family environment ${ }^{*}$ Compassion & & & & -0.032 & $-0.067 ; 0.004$ & 0.079 \\
\hline \multicolumn{7}{|l|}{ TNF- $\alpha$} \\
\hline Risky family environment & 0.037 & $0.004 ; 0.070$ & 0.028 & 0.277 & $0.087 ; 0468$ & 0.004 \\
\hline Compassion & & & & 0.047 & $0.001 ; 0.093$ & 0.044 \\
\hline Risky family environment ${ }^{*}$ Compassion & & & & -0.066 & $-0.117 ;-0.014$ & 0.012 \\
\hline
\end{tabular}

$* p<.05 * * p<.01 * * * p<.001$

Models were adjusted for age, sex, the use of anti-inflammatory medications, inflammatory diseases, socioeconomic factors in childhood and adulthood, body-mass index, and health behavior (smoking, alcohol use, alcohol intoxication, and physical activity).

Note: All the cytokines were set as outcome variables simultaneously. 


\section{Emotional environment, compassion and cytokines}

Supplementary Table 3. The results of the multivariate multiple regression analyses, when predicting the logarithm-transformed cytokine levels in 2007 by compassion in 2001.

\begin{tabular}{|c|c|c|c|c|c|c|}
\hline & \multicolumn{3}{|c|}{ Model $1(\mathrm{~N}=1523)$} & \multicolumn{3}{|c|}{ Model $2(\mathrm{~N}=1198)$} \\
\hline & $\mathrm{B}$ & $95 \% \mathrm{CI}$ & $\mathrm{p}$ & $\mathrm{B}$ & $95 \% \mathrm{CI}$ & $\mathrm{p}$ \\
\hline IL-2 & 0.000 & $-0.034 ; 0.035$ & 0.989 & -0.007 & $-0.049 ; 0.035$ & 0.755 \\
\hline IL-6 & -0.002 & $-0.035 ; 0.031$ & 0.898 & 0.000 & $-0.041 ; 0.040$ & 0.988 \\
\hline IL-1b & 0.006 & $-0.018 ; 0.030$ & 0.622 & 0.005 & $-0.023 ; 0.034$ & 0.714 \\
\hline MCP-1 & -0.004 & $-0.031 ; 0.023$ & 0.757 & 0.005 & $-0.028 ; 0.037$ & 0.784 \\
\hline IFN- $\gamma$ & 0.001 & $-0.023 ; 0.025$ & 0.933 & 0.006 & $-0.023 ; 0.034$ & 0.683 \\
\hline TNF- $\alpha$ & 0.006 & $-0.029 ; 0.041$ & 0.732 & 0.007 & $-0.035 ; 0.049$ & 0.733 \\
\hline
\end{tabular}

$* p<.05 * * p<.01 * * * p<.001$

Model 1 was adjusted for age, sex, the use of anti-inflammatory medications, and inflammatory diseases.

Model 2 was adjusted also for socioeconomic factors in childhood and adulthood, body-mass index, health behavior (smoking, alcohol use, alcohol intoxication, and physical activity), and depressive symptoms.

Note: All the cytokines were set as outcome variables simultaneously. 